\title{
Intergenerational Support and Life Satisfaction: A Comparison of Chinese, Indonesian, and German Elderly Mothers
}

\author{
Beate Schwarz', Isabelle Albert ${ }^{2}$, \\ Gisela Trommsdorff ${ }^{3}$, Gang Zheng ${ }^{4}$, \\ Shaohua Shi ${ }^{4}$, and Peter R. Nelwan ${ }^{5}$
}

\begin{abstract}
The exchange of support between generations is a fundamental feature of intergenerational relationships. Although most studies have concentrated on the impact of social support on the receiver, effects on subjective well-being of the provider of support have been studied less often. Given cultural differences in the norms and values of intergenerational relationships, the present study compared samples from rural and urban China, Indonesia, and Germany. The results showed that in the different cultural contexts elderly mothers' well-being was differently related to help that they provided to their adult daughters. The results are discussed from a culture-informed perspective on intergenerational relationships.
\end{abstract}

\section{Keywords}

family, old age, subjective well-being

The Value of Children and Intergenerational Relations study (VOC study) focuses on intergenerational relations from adolescence to old age. One of the theoretical bases of the study is the culture-informed model of intergenerational relationships across the life span (Trommsdorff, 2006), which assumes influences of the cultural and socioeconomic context on relationship aspects (e.g., relationship quality and exchange of support) in line with the meaning of cultural values and norms. Following this theoretical model, the exchange of support between generations is a fundamental feature of intergenerational relationships. The importance of intergenerational support has been shown across a variety of cultures (e.g., Kohli, Künemund, Motel, \& Szydlik, 2000; Sun, 2002). The quantity and quality of the exchange of support are associated

\footnotetext{
'University of Basel, Basel, Switzerland

${ }^{2}$ University of Luxembourg, Walferdange, Luxembourg

${ }^{3}$ University of Konstanz, Konstanz, Germany

${ }^{4}$ Chinese Academy of Sciences, Beijing, China

${ }^{5}$ Padjadjaran University, Bandung, Indonesia

\section{Corresponding Author:}

Beate Schwarz, University of Basel, Department of Psychology, Missionsstr. 62a, 4055 Basel, Switzerland

Email: beate.schwarz@unibas.ch
} 
with norms of family obligations and the relationship quality (Schwarz, Trommsdorff, Albert, \& Mayer, 2005), and they are influenced by the needs of the receiver and the resources of the provider (Sun, 2002). In line with the assumptions of Trommsdorff (2006), recent studies based on the VOC data have shown culture-specific patterns of associations between different aspects of relationships (Schwarz \& Trommsdorff, 2005; Schwarz, Trommsdorff, Kim, \& Park, 2006; Schwarz, Trommsdorff, Zheng, \& Shi, in press; Trommsdorff \& Schwarz, 2007).

Although several studies have investigated the impact of social support on the receiver, less is known about the effects of providing support within the family. On one hand, providing support could be a burden for the support giver (e.g., Schwarz et al., 2005); on the other hand, it could be a source of self-efficacy and social approval by others and thereby a basis of one's life satisfaction (Lowenstein, Katz, \& Gur-Yaish, 2007; Ryff \& Keyes, 1995). Elderly persons have to cope with their increasing health problems and impairments and in many cultures with a loss of social roles and social importance. Being able to still provide at least some support could serve as compensation for these losses and thus might be beneficial for the well-being of the elderly. Therefore, we investigated the meaning of providing social support to adult daughters for elderly mothers' well-being, particularly their life satisfaction. As cultures differ remarkably with regard to norms for intergenerational relationships, family obligations, and the role of the elderly, we compared the possible associations between providing support and life satisfaction among elderly mothers from three countries: China, Indonesia, and Germany. Thus, the present study broadens the perspective of the culture-informed model of intergenerational relations (Trommsdorff, 2006) and examines the question of the emotional utility of intergenerational relations in old age. Often this question is dealt within sociological approaches of action theory, a further theoretical basis of the VOC study (e.g., Nauck, 2005). However, the present study follows a more psychological framework.

\section{Intergenerational Relationships in China}

The prolonged life expectancy over the past decades together with the dramatic fertility decline because of the one-child policy have led to a growing elderly population in China. Today, the percentage of those aged 65 and older is $8 \%$. However, according to Q. F. Zhang (2004), only 17\% of the population aged 60 years and older has access to a pension. Thus, elderly parents depend on their adult children, who are still the primary source of old-age support to their parents (Sheng, 2005). At least among urban Chinese families, financial and material support is more often provided by adult children than is help with daily activities (Sun, 2002).

China is the country of origin of Confucianism (see Zheng, Shi, \& Tang, 2005). According to Confucianism, family members are connected through mutual interdependence over the lifetime. Lifelong loyalty as well as the maintenance of harmony in the family are expected. Adult children, especially the eldest son and his wife, have to fulfill the duty of caring for the elderly parents in a material, emotional, and spiritual way (Ho, 1996; Hwang, 1999).

Over the past decades, East Asian countries have undergone rapid social changes with a profound effect on parent-child relationships (Trommsdorff, 1998, 2006). For instance, the parentchild relationship has become less characterized by hierarchy and subordination (Chen \& Silverstein, 2000). However, the modernization experienced by East Asian countries has not eliminated traditional values (Trommsdorff, 1998; Wang \& Hsueh, 2000). Many authors agree that Confucian norms continue to be important in China (Ho, 1996; Zheng et al., 2005) and that family obligations and high respect for parents are still prevalent in parent-child relationships (Fuligni, Yip, \& Tseng, 2002; Wang \& Hsueh, 2000; Yue \& Ng, 1999).

In China, the large differences between the urban and rural populations are striking. Urban areas are characterized by higher degrees of modernization and economic wealth, whereas beliefs 
in traditional values are lower (see Sheng, 2005; Zheng et al., 2005). With respect to old-age security, a higher percentage of the elderly in urban compared to rural areas receives at least some pension.

\section{Intergenerational Relationships in Indonesia}

The Indonesian population is also aging rapidly. The percentage of people older than the age of 65 years is now 6\% (Population Reference Bureau, 2008).

Few formal provisions for the elderly, such as general state pension plans, universal health coverage, and institutional care, exist so far. The majority of Indonesian elderly people remain economically active and financially independent. However, apart from self-reliance regarding old-age provision, the family has an important role in providing support, especially when elderly persons become frail or ill (Kreager, 2006).

Indonesia is a complex and diversified country and includes many different ethnic groups. The largest ethnic group is the Javanese ( $45 \%$ of the Indonesian population), living in East and Central Java, followed by the Sundanese (14\% of the Indonesian population) in West Java (Central Intelligence Agency, 2004), the latter group containing the sample of the current study. Within both the Javanese and the Sundanese ethnic groups, social relations are hierarchically organized with a primary value being respect for higher ranking persons (Magnis-Suseno, 1989; Mulder, 1992, 2000; Pidada, 1993). High importance is attributed to harmony in social relations, and open conflicts are generally avoided (Geertz, 1961).

The hierarchy in the parent-child relationship remains stable over the life course. Parents are obliged to care for their children and provide them everything they need to grow up (Mulder, 1992). The parents' responsibility for their children extends into their offspring's adulthood in the sense that they contribute to their children's economic security, and it is socially expected that parents will support their children in times of need (Schröder-Butterfill, 2003). As it is not possible to become indebted to a superior according to the traditional belief, children are not expected to "pay back" their parents' efforts. However, adult children have obligations to honor their parents and to respect them (Mulder, 1992, 2000; Schröder-Butterfill, 2003).

According to Mulder (2000), social change, in the form of growing social and geographic mobility, has altered the traditional way of life in Indonesia. This is reflected in differences between urban and rural residents as far as importance of traditional values is concerned. For example, Albert, Trommsdorff, Mayer, and Schwarz (2005) report that rural Indonesian respondents of the VOC study adhered more to social-normative values of children than did their urban counterparts.

\section{Intergenerational Relationships in Germany}

In Germany, $22 \%$ of the German population is now 65 years and older (Bundesinstitut für Bevölkerungsforschung, 2008). The German old-age security system provides a full pension for all former employed persons and a share for their partners.

Germany, as a culture based on a Christian tradition, is also characterized by an obligation of mutual support of family members. At the same time, Germany can be characterized as an individualistic culture in which independent orientations prevail (Hofstede, 2001; Oyserman, Coon, \& Kemmelmeier, 2002). This concomitance is reflected in adult parent-child relationships. It is rare in Germany that three generations live under one roof (Klaus, Nauck, \& Klein, 2005). Nevertheless, strong emotional bonds and frequent contact between the generations of a family are often observed (Kohli et al., 2000). As a result of relatively secure old-age pensions, it is rare that children support their elderly parents financially. Instead, many parents have an income large 
enough to help their children if they are in need. Beyond financial support, the exchange of instrumental and emotional support is more often balanced between parents and children (Kohli et al., 2000). Thus, for the greater part of life, more support flows from parents to their children than vice versa, even in adulthood; this is especially true for financial support. Furthermore, it seems that a deviation from this support pattern is associated with tensions in the adult parentchild relationships (Schwarz et al., 2005).

In sum, we compare intergenerational relations in samples from three cultures that differ with respect to the structure of the social security system and the norms and values concerning intergenerational support. In China almost no old-age security system is available. In addition, Confucian values point to strong obligations of the adult children to support their elderly parents. In Indonesia as well, the government does not provide old-age pensions; however, the parents try to stay financially independent from their children. According to the norm, parents support their children when they are in need, even in adulthood. In Germany, because of strong old-age pensions, elderly parents are financially independent from their children, whereas with respect to other kinds of support they can rely on their children. The norms for intergenerational support are less clear; in general, they rather favor mutual support.

\section{Life Satisfaction}

In the context of research on quality of life and well-being in old age, life satisfaction has often been studied as a major concept. Life satisfaction is conceived of as the cognitive component of subjective well-being as it refers to evaluations of one's life or specific life domains, whereas other aspects, such as happiness or positive and negative emotions, represent affective components (cf. Diener, Suh, Lucas, \& Smith, 1999). In this view, life satisfaction includes the subjective appraisal of one's specific and general life situation (e.g., Ferring et al., 2004). The importance of these subjective appraisals is underlined by only weak to moderate links between objective characteristics such as income, health, and education and subjective well-being as found in many studies (Diener et al., 1999).

Because of several losses that are common in old age, one would expect lower life satisfaction for older persons; however, no clear empirical evidence for an age-related decline exists, which is often referred to as the aging paradox (Diener et al., 1999; Kunzmann, Little, \& Smith, 2000). This is in line with the results from a longitudinal study in Germany, which reported only a slight decline in life satisfaction with age (Schilling, 2006). A cross-sectional study of Chinese adolescents and adults showed an increase in life satisfaction with age (L. Zhang, 2005).

Many factors have demonstrated effects on life satisfaction and subjective well-being. Among these are personality variables, adaptive cognitive mechanisms (e.g., adaptation of personal goals or comparison processes), social relationships, and biographical variables (e.g., Diener et al., 1999).

In different cultures, different factors may account for life satisfaction, depending on the dominant cultural orientations and values (Diener, 2000; Suh, Diener, Oishi, \& Triandis, 1998). However, cross-cultural comparisons have rarely been done. For China, Yeung and Fung (2007) showed that older persons who scored high on familism also showed a stronger relationship between instrumental support received from family members and life satisfaction. Furthermore, personality variables such as extraversion, neuroticism, and self-esteem also contribute to life satisfaction of Chinese adults (L. Zhang, 2005).

\section{Associations Between Providing Support and Life Satisfaction}

Social relationships, and especially family relations, represent one of the most important life domains related to life satisfaction and subjective well-being (e.g., Askham, Ferring, \& Lamura, 
2007; Caprara \& Steca, 2006; Ryff \& Keyes, 1995). Especially for elderly persons, emotional closeness with family members becomes more important relative to relationships with persons who are less close in the social network (Lang \& Carstensen, 2002). Thus, one can expect that the quality of the family relationships is strongly related to elderly mothers' life satisfaction.

As reported before, the exchange of social support is a fundamental feature of family relationships, independent of culture or social security system. With respect to the association between social support and well-being, most research has examined the well-being of adult children as caregivers of old and frail parents or the well-being of elderly parents receiving support from children. Less is known about the relation between elderly parents' provision of support and their well-being. However, contrary to the often assumed recipient role of older people, older people are often involved in helping behavior, and there are reasons to believe that there is a positive and direct association between provision of support by elderly people and their well-being (Midlarsky \& Kahana, 1994).

First, the experience of autonomy and self-efficacy is important for psychological well-being during the whole life span (Caprara \& Steca, 2006; Perrig-Chiello, 1997; Ryff \& Keyes, 1995). Because old age is accompanied by losses in physical capacity, social roles, and relationships, the ability to provide support to others may be seen as an indicator of one's self-reliance and social efficacy. As Rowe and Kahn (1998) argue, one important factor for successful aging might be to stay active. In line with these arguments, Lowenstein et al. (2007) showed for four European countries and Israel that serving as an active provider of support to adult children was positively related to life satisfaction of elderly parents. In contrast, receiving support was negatively associated with life satisfaction. Therefore, one may conclude that demonstrating self-efficacy by providing support will contribute to well-being of elderly persons in Western cultures.

This assumption seems to be true also for Asian cultures. For elderly people in Taiwan, physical health and autonomy were the most often mentioned characteristics of successful aging (Hsu, 2007). Also, Chen and Silverstein (2000) demonstrated that older Chinese parents' provision of instrumental support to children was positively related to parents' well-being. As most elderly Chinese must rely financially on their children in old age, the provision of instrumental support might give them the possibility to reciprocate the financial support that they receive and also might enhance their power in the family by enabling them to fulfill indispensable practical tasks (e.g., household chores or child care) for adult children.

Second, taking culture into account, parents from cultures where values to support adult children prevail, as is the case in Indonesia and Germany, psychologically benefit from providing support. Presumably, when these parents provide support for their children, they believe they are fulfilling their duties to the next generation. Because this behavior is in line with cultural values, this may improve their life satisfaction. The results of an empirical study by Efklides, Kalaitzidou, and Chankin (2003) support this hypothesis. For a sample of Greek elderly people, the authors report a positive relation between elderly parents' life satisfaction and providing support for their children and grandchildren.

Beside these direct positive associations between providing support and life satisfaction, indirect relations are also possible. The maintenance of a positive relationship with adult children might be an explanation for the positive association between providing support and life satisfaction. Especially for elderly persons, close relations with family members are important (Lang \& Carstensen, 2002). There is strong evidence for a positive association between quality of intergenerational relationships and more frequent provision of support by parents, in Western as well as Asian cultures (e.g., Rossi \& Rossi, 1990; Schwarz \& Trommsdorff, 2005). In turn, at least in Western cultures, affective intergenerational relationships seem to be related to parents' well-being (Lang \& Schütze, 2002; Umberson, 1992). Thus, improved quality of the adult parent-child relationship might mediate the association between provision of social support and life satisfaction. 
In sum, the major research question of this study was whether providing support to adult children (here adult daughters) is associated with elderly parents' (here elderly mothers') life satisfaction and whether this holds true among Chinese, Indonesian, and German women. We expected a positive association at least for the Indonesian and German mothers. In addition, we hypothesized that mothers' perception that their daughters value them highly would explain the positive association between provision of support and life satisfaction. However, given the large differences between urban and rural populations in China and Indonesia, differences in the associations between both samples within each culture will also be examined. We expected that the rural samples would follow a more traditional pattern within their culture. Because the importance of approval by the daughters might be a typical feature in more individualistic cultures, we expected a mediational effect of admiration only for the German and the urban samples. Finally, in an exploratory analysis, we investigate differential effects of three kinds of support, emotional, instrumental, and financial support, as these require different resources on the part of the provider.

\section{Method}

\section{Procedures}

This study is part of the cross-cultural VOC study (Trommsdorff \& Nauck, 2005). The procedures of recruitment were adapted to the specific circumstances of the respective countries and pretested for comparability (e.g., bias, equivalence of measurements) in pilot studies by the local coinvestigators.

The Chinese and Indonesian samples were recruited through the schools of the target population's grandchildren and in China also through inhabitant lists of neighborhood committees. The German sample was recruited through residents' registration offices (also see Albert et al., 2005, for the Indonesian sample; Mayer, Albert, Trommsdorff, \& Schwarz, 2005, for the German sample; Zheng et al., 2005, for the Chinese sample).

The Chinese participants were recruited from Beijing Municipality, Henan Province, Yunnan Province, and Guangxi Zhuang Autonomous Region. The interviews in Indonesia were conducted in the city and the rural surroundings of Bandung in West Java. Most participants were Sundanese. The German sample was recruited in two middle-size cities, Chemnitz and Constance, and in one large city, Essen. No differentiation between urban and rural samples was intended.

The participation was voluntary, and confidentiality was ensured. In all countries, the data collection was comparable: Trained female interviewers carried out the standardized face-to-face interviews at the home of the women. At the end of the interviews, the respondents received a small gift.

The language of the basic questionnaire was English. In line with established procedures for cross-cultural research to ensure comparability (Van de Vijver \& Leung, 1997), the questionnaire was then translated into Chinese, Bahasa Indonesia, and German by the local research teams and subsequently back translated. The translations were intensively discussed within the local teams and revised when necessary.

\section{Participants}

The VOC study comprised three generations: grandmothers, their adult daughters, and an adolescent child of the daughters (see Trommsdorff \& Nauck, 2005). Here, we refer only to the perspective of the grandmothers (in the following, elderly mothers) on their relationship with their daughter.

In China, $n=207$ elderly mothers were interviewed, $n=111$ from rural areas and $n=96$ mothers from urban areas. In Indonesia, $n=100$ elderly mothers were interviewed, 50 mothers 
each from rural and urban areas. For Germany, interviews with $n=99$ elderly mothers were conducted.

The mean age of the Chinese mothers was $64.69(S D=6.41)$ for rural and $68.04(S D=4.60)$ for urban mothers; the mean age of Indonesian mothers was $58.00(S D=6.64)$ for rural and $67.16(S D=6.72)$ for urban mothers. The mean age of German elderly mothers was $69.57(S D=$ 5.92 ). A one-way analysis of variance with post hoc Bonferroni tests, $F(4,355)=20.62, p<.001$, showed that the Indonesian mothers from rural areas were significantly younger than all other subsamples. The Chinese mothers from rural areas were younger than the Chinese urban and the German mothers. Among the elderly mothers from rural China, almost $70 \%$ were married, with $30 \%$ widowed, and among urban Chinese mothers the respective numbers were $64 \%$ and $35 \%$. In the Indonesian sample, $52 \%$ of the rural and $40 \%$ of the urban mothers were married, and $36 \%$ and $58 \%$ were widowed. In the German sample, $53 \%$ of the mothers were married and $40 \%$ were widowed. All others were separated or divorced.

With respect to education, the mean of completed years in school for the Chinese mothers were $5.75(S D=4.54)$ for the urban and $2.28(S D=2.98)$ for the rural sample. The respective means for urban and rural Indonesian mothers were 5.63 years $(S D=3.64)$ and 4.62 years $(S D=$ $2.32)$ and for the German mothers 9.02 years $(S D=1.81)$. According to the one-way analysis of variance with post hoc Bonferroni tests, $F(4,392)=50.20, p<.001$, German mothers' education was significantly higher and rural Chinese mothers' education was significantly lower compared to all other groups.

In the rural Chinese sample, $7 \%$ of the mothers were employed; in the urban Chinese sample, $8 \%$ of the mothers were employed. Among rural and urban Indonesian mothers, $16 \%$ were employed. In the German group, 9\% of the mothers were employed (see Albert et al., 2005; Mayer et al., 2005; Zheng et al., 2005).

As this study investigated intergenerational support, some information about structural aspects of the relationship with the daughter was examined. Here, we refer to reports of the adult daughters because no reports of the elderly mothers were available. With respect to the frequency of face-to-face contact, $44 \%$ of the rural and $62 \%$ of the urban Chinese daughters reported to have contact more than once a week, $40 \%$ and $30 \%$ reported to have contact at least once a month, and $14 \%$ and $4 \%$ had contact less than once a month. In the Indonesian sample, $98 \%$ of the rural and $92 \%$ of the urban women reported contact more than once a week. In the rural sample, the remaining $2 \%$ had contact at least once a month. In the urban sample, $4 \%$ each had contact once a month or less than once a month. In the German sample, $76 \%$ of the mother-daughter dyads had contact more than once a week, $22 \%$ at least once a month, and $2 \%$ less often.

With respect to geographical proximity of the generations, in the rural Chinese sample $6 \%$ lived in the same household, $43 \%$ within 15 minutes, and 51\% further away. In the urban Chinese sample, 33\% lived together in one household, 19\% within 15 minutes, and $48 \%$ further away. Among rural Indonesian mothers, 22\% lived in the same household, 76\% within 15 minutes, and $2 \%$ further away. In the urban sample, the respective numbers were $45 \%, 43 \%$, and $12 \%$. In the German sample, only 2\% lived together in the same household but 54\% lived within 15 minutes and $44 \%$ further away. These figures are not representative of the household constellations in the different areas because, for practical reasons, only those dyads that were within reach for the interviewers were recruited.

\section{Measures}

All measures refer to self-reports of the elderly mothers given in a standardized oral interview.

Social support given to the adult daughter. Mothers were asked about actual support given to the adult daughter in the past 12 months. Three kinds of support were measured: emotional 
(three items: "In the last 12 months: How often have you given advice to your daughter?" "How often have you tried to comfort your daughter?" "How often have you talked with your daughter about her worries or sorrows?" Cronbach's alphas: China $=.73$, Indonesia $=.78$, Germany $=$ .76), instrumental (two items: "In the last 12 months: How often have you done chores like shopping or housekeeping for your daughter?" "How often have you taken care of your daughter when she was ill or laid up?" China $r=.56$, Indonesia $r=.63$, Germany, $r=35, p \mathrm{~s}<.05$ ), and financial support (one item: "How often have you given your daughter financial support in the last 12 months?"). All items were rated on a 5 -point scale $(1=$ never to $5=$ always $)$.

Admiration by daughter. One subscale of the Network of Relationship Inventory (Furman \& Buhrmester, 1985) that assessed the elderly mothers' perceptions of how much their daughters admire them was included (three items; e.g., "How often does your daughter let you know that you are good at many things?"). Cronbach's alphas were .77 (China), .65 (Indonesia), and .71 (Germany). The respondents rated the three items on a 5 -point scale $(1=$ never to $5=$ always $)$.

Maternal life satisfaction. One item was used: "All things considered, how satisfied are you with life as a whole these days?" This one-item indicator has often been adopted in studies by Diener and colleagues as a valid measure of general life satisfaction (e.g., Diener, Gohm, Suh \& Oishi, 2000; Fujita \& Diener, 2005; also see Tesch-Römer, Motel-Klingebiel, \& von Kondratowitz, 2002).

\section{Results}

\section{Preliminary Analyses}

Differences among the five samples (rural and urban samples from China and Indonesia and the German sample) with respect to all indicators were tested using one-way analyses of variance with post hoc Bonferroni tests. The respective means and standard deviations are provided in Table 1. These analyses indicated a significant difference among groups in emotional support given by the mother, $F(4,401)=17.50, p<.001$. Post hoc tests indicated that German mothers provided less emotional support than did all other mothers. In addition, the rural Chinese mothers' emotional support was lower compared to both samples from Indonesia. German mothers also provided less instrumental support than all other mothers. Instrumental support of urban Chinese mothers was lower than the support of rural Chinese and urban Indonesian mothers, $F(4$, $401)=18.79, p<.001$. With respect to financial support, German mothers' support was lower compared to the urban Chinese and both Indonesian samples. The rural Chinese mothers provided less financial support than the urban Chinese mothers, $F(4,400)=9.79, p<.001$. German mothers perceived more admiration by their daughters than did the mothers from both Chinese samples and from rural Indonesia, $F(4,401)=5.54, p<.001$. The German mothers also reported higher life satisfaction than the rural Chinese and both groups of Indonesian mothers, $F(4,400)=$ $5.81, p<.001$

\section{Mothers' Life Satisfaction Predicted by Social Support Given and Daughters' Admiration}

Hierarchical regression analyses were conducted to predict elderly mothers' life satisfaction separately for the Chinese, Indonesian, and German samples. In a first step, the three indicators of social support given by the mother were included; in a second step, admiration was added. A reduction of the effects of social support and a simultaneous significant effect of admiration by daughters would point to a mediation effect of admiration for the association between social support and life satisfaction (Baron \& Kenny, 1986). The Chinese and Indonesian samples were 
Table I. Means and Standard Deviations for Social Support Given by the Mother, Daughters' Admiration, and Mothers' Life Satisfaction, Separately for the Rural and Urban Chinese and Indonesian and German Samples

\begin{tabular}{|c|c|c|c|c|c|c|c|c|c|c|}
\hline & \multicolumn{2}{|c|}{$\begin{array}{l}\text { Emotional } \\
\text { support }\end{array}$} & \multicolumn{2}{|c|}{$\begin{array}{l}\text { Instrumental } \\
\text { support }\end{array}$} & \multicolumn{2}{|c|}{$\begin{array}{l}\text { Financial } \\
\text { support }\end{array}$} & \multicolumn{2}{|c|}{$\begin{array}{l}\text { Daughter's } \\
\text { admiration }\end{array}$} & \multicolumn{2}{|c|}{$\begin{array}{c}\text { Life } \\
\text { satisfaction }\end{array}$} \\
\hline & $M$ & $S D$ & $M$ & $S D$ & $M$ & $S D$ & $M$ & $S D$ & $M$ & $S D$ \\
\hline China rural (CR) & 2.51 & 0.76 & 2.31 & 0.97 & 1.76 & 0.98 & 2.77 & 1.00 & 3.88 & 0.74 \\
\hline China urban (CU) & 2.74 & 0.93 & 2.84 & 1.12 & 2.24 & 1.01 & 2.67 & 0.93 & 3.97 & 0.81 \\
\hline Indonesia rural (IR) & 2.99 & 1.02 & 2.62 & 1.08 & 2.18 & 0.90 & 2.62 & 0.84 & 3.82 & 0.77 \\
\hline Indonesia urban (IU) & 2.90 & 0.82 & 2.33 & 1.05 & 2.10 & 0.89 & 2.89 & 0.78 & 3.74 & 0.92 \\
\hline Germany (G) & 2.02 & 0.67 & 1.66 & 0.78 & $|.5|$ & 0.86 & 3.18 & 0.76 & 4.28 & 0.67 \\
\hline Post hoc Bonferroni & \multicolumn{2}{|c|}{$\begin{array}{c}G<\text { all; } C R< \\
I R, I U\end{array}$} & \multicolumn{2}{|c|}{$\begin{array}{c}\mathrm{G}<\text { all } ; \mathrm{CU}> \\
\mathrm{CR}, \mathrm{IU}\end{array}$} & \multicolumn{2}{|c|}{$\begin{array}{c}\mathrm{G}<\mathrm{CU}, \mathrm{IR}, \mathrm{IU} ; \\
\mathrm{CR}<\mathrm{CU}\end{array}$} & \multicolumn{2}{|c|}{$\begin{array}{c}\mathrm{G}>\mathrm{CR}, \\
\mathrm{CU}, \mathrm{IR}\end{array}$} & \multicolumn{2}{|c|}{$G>C R, I R, I U$} \\
\hline
\end{tabular}

composed of mothers from rural and urban areas. Because social change differs remarkably between rural and urban areas in these countries, we further investigated whether the associations among social support, daughters' admiration, and life satisfaction differed for the rural and urban samples within each culture.

Therefore, a dummy variable for region $(0=$ rural, $1=$ urban $)$ was included in the first step of the regression analyses regarding the Chinese and the Indonesian samples. Furthermore, in a third step, the interactions between region and the indicators of social support and daughters' admiration were added. Following a suggestion by Aiken and West (1991), all continuous indicators were centered within the respective culture. If an interaction effect became significant, we further probed the interaction by evaluating the simple slopes of the indicators of support or daughters' admiration within both levels of the region variable. Therefore, we conducted two separate regression analyses in which each group in turn served as the reference group (Aiken \& West, 1991). Table 2 provides the intercorrelations of all indicators separately for rural and urban Chinese and Indonesian and for German mothers.

If elderly mothers have limited resources, providing support could be a burden for them. In this case, life satisfaction might not be positively related to support given. Therefore, all analyses were also run with demographic control variables, which might be proxies of the resources: education, age of the mother, and number of children. However, none of these variables were related to life satisfaction, and their inclusion did not change the other effects substantially. For reasons of parsimony, we decided to report the analyses without the control variables.

Chinese mothers. Table 3 shows that none of the three kinds of social support was associated with maternal life satisfaction. However, a positive association between daughters' admiration and maternal life satisfaction occurred in the second step. The higher the perceived admiration from their daughters was, the higher their maternal life satisfaction. A third step of the regression analysis was used to test whether the mothers from rural and urban regions differed with respect to the associations. However, no rural-urban differences were found.

Indonesian mothers. The same analysis was conducted for the mothers from the Indonesian sample (see Table 4). First, we found a positive association between financial support provided by the mothers to their daughters and maternal life satisfaction. The more financial support they had given, the higher their life satisfaction. Admiration by their daughter was not related to maternal life satisfaction. However, the third step of the regression analysis pointed to differences in the association between admiration and life satisfaction for the rural and urban sample. Additional analyses showed that a positive association was found among mothers from urban regions $(\beta=.41, p<.01)$ but not for mothers in rural areas $(\beta=-.06, n s)$. 
Table 2. Intercorrelations of Indicators of Social Support, Admiration, and Life Satisfaction, Separately for Rural Chinese (CR, $n=1 \mathrm{II})$, Urban Chinese $(C U, n=96)$, Rural Indonesian (IR, $n=50)$, Urban Indonesian (IU, $n=50)$, and German (G, $n=99)$ Mothers

\begin{tabular}{|c|c|c|c|c|c|c|}
\hline & Country & 1 & 2 & 3 & 4 & 5 \\
\hline \multirow[t]{5}{*}{ I. Emotional support } & CR & - & $.34 *$ & $.28 *$ & $.17 *$ & -.08 \\
\hline & CU & 一 & $.49 *$ & $.40 *$ & $.23 *$ & .07 \\
\hline & IR & 一 & $.25 *$ & $.43^{*}$ & .16 & .18 \\
\hline & IU & 一 & .15 & .15 & .12 & .02 \\
\hline & G & 一 & $.30 *$ & $.32 *$ & $.36 *$ & -.02 \\
\hline \multirow[t]{5}{*}{ 2. Instrumental support } & $C R$ & & - & $.21 *$ & -.05 & .05 \\
\hline & CU & & - & $.32 *$ & $.22^{*}$ & .10 \\
\hline & IR & & - & .19 & .18 & -.04 \\
\hline & IU & & - & .08 & .01 & -.14 \\
\hline & G & & - & $.35 *$ & $.26 *$ & $.25 *$ \\
\hline \multirow[t]{5}{*}{ 3. Financial support } & CR & & & - & $.24 *$ & -.15 \\
\hline & CU & & & - & -.08 & -.04 \\
\hline & IR & & & - & .11 & $.34 *$ \\
\hline & IU & & & - & $.29 *$ & .16 \\
\hline & G & & & - & .12 & .13 \\
\hline \multirow[t]{5}{*}{ 4.Admiration } & CR & & & & - & .01 \\
\hline & $\mathrm{CU}$ & & & & - & $.30 *$ \\
\hline & IR & & & & - & -.03 \\
\hline & IU & & & & - & $.38 *$ \\
\hline & G & & & & - & $.31 *$ \\
\hline 5. Life satisfaction & & & & & & - \\
\hline
\end{tabular}

$* p<.05$.

Table 3. Hierarchical Regression Analysis to Predict Chinese Elderly Mothers' Life Satisfaction by Social Support Given to the Adult Daughter and Admiration by Daughter With a Comparison of Rural and Urban Samples

\begin{tabular}{|c|c|c|c|}
\hline & Step I & Step 2 & Step 3 \\
\hline & $\beta$ & $\beta$ & $\beta$ \\
\hline Urban $(U)^{\mathrm{a}}$ & .06 & .07 & .07 \\
\hline Emotional support (ES) & -.00 & -.03 & -.09 \\
\hline Instrumental support (IS) & .12 & .12 & .13 \\
\hline Financial support (FS) & -.13 & -.14 & -.17 \\
\hline Daughter's admiration (A) & & $.15^{*}$ & .07 \\
\hline $\mathrm{U} \times \mathrm{ES}$ & & & .06 \\
\hline$U \times I S$ & & & -.05 \\
\hline $\mathrm{U} \times \mathrm{FS}$ & & & .09 \\
\hline$U \times A$ & & & .16 \\
\hline
\end{tabular}

a. Reference group is rural mothers.

$*_{p}<.05$.

German mothers. As shown in Step 1 of Table 5, provision of instrumental support was positively associated with life satisfaction of the mothers. The more instrumental help the mothers had given, the higher their life satisfaction. This effect was partly reduced after the introduction of the significant effect of daughters' admiration in Step 2 of the analysis. Thus, the admiration the 
Table 4. Hierarchical Regression Analysis to Predict Indonesian Elderly Mothers' Life Satisfaction by Social Support Given to the Adult Daughter and Admiration by Daughter With a Comparison of Rural and Urban Samples

\begin{tabular}{|c|c|c|c|}
\hline & Step I & Step 2 & Step 3 \\
\hline & $\beta$ & $\beta$ & $\beta$ \\
\hline Urban $(U)^{\mathrm{a}}$ & -.05 & -.08 & -.09 \\
\hline Emotional support (ES) & .05 & .04 & .06 \\
\hline Instrumental support (IS) & -.14 & -.15 & -.10 \\
\hline Financial support (FS) & $.24 *$ & $.22 *$ & $.31^{*}$ \\
\hline Daughter's admiration (A) & & .15 & -.06 \\
\hline$U \times E S$ & & & -.05 \\
\hline$U \times I S$ & & & -.05 \\
\hline$U \times F S$ & & & -.16 \\
\hline$U \times A$ & & & $.32^{*}$ \\
\hline
\end{tabular}

a. Reference group is rural mothers.

$* p<.05$.

Table 5. Hierarchical Regression Analysis to Predict German Elderly Mothers' Life Satisfaction by Social Support Given to the Adult Daughter and Admiration by Daughter

\begin{tabular}{lcc}
\hline & Step I & $\frac{\text { Step 2 }}{$\cline { 2 - 3 }} \\
\cline { 2 - 3 } & $\beta$ & $\beta$ \\
\hline Emotional support & -.12 & $-.22^{*}$ \\
Instrumental support & $.25^{*}$ & .20 \\
Financial support & .08 & .09 \\
Daughter's admiration & & $.33^{* *}$ \\
\hline
\end{tabular}

$*_{p}<.05 . *_{p}<.01$.

mothers perceived from their daughters partly explained the positive relationship between the provision of instrumental support and maternal life satisfaction. In addition, a suppressor effect was observed. After controlling for daughters' admiration, provision of emotional support was negatively associated with maternal life satisfaction. The more emotional support the mothers had given, the lower their life satisfaction. The provision of financial support was not related to life satisfaction. For the German sample, no comparison of rural and urban samples was possible.

Differences among the cultures. Additional analyses were conducted to test whether the observed associations in the two Asian samples differed significantly from the associations in the German sample. Here, no differentiations between urban and rural samples were made. Only one difference was significant: the comparison between the Indonesian and German sample for the association between instrumental support and life satisfaction (interaction between culture and instrumental support: $\beta=-.19, p<.05)$.

\section{Discussion}

The aim of the present study was to investigate the impact of elderly mothers providing support for their adult daughters on their life satisfaction in three different cultural contexts. China, Indonesia, and Germany were selected because they differ with respect to values related to intergenerational 
relationships and the old-age security systems. The results with respect to relations among support provided by elderly mothers to their adult daughters, admiration by daughters, and life satisfaction differed depending on the region and also the kind of support. In the following paragraphs, the culture-specific findings are discussed from a culture-informed perspective in line with the methodological goals of the VOC study (Trommsdorff, 2006).

For Chinese mothers, we did not find associations between support given and life satisfaction. On the one hand, support provision to adult children is not in line with traditional Chinese obligations within a family (Ho, 1996; Hwang, 1999). If elderly parents have to support an adult child, who is usually obliged to support them, this might be a sign that the parents have failed to raise a successful child and thus have failed to fulfill their parental obligation. On the other hand, Confucian values of the family also require mutual support and loyalty of all family members (Hwang, 1999; Wang \& Hsueh, 2000). Thus, the lack of a correlation may also be because of individually different effects of support provision: for some elderly mothers, it may be detrimental to provide support for their adult daughters, whereas for others it may also be positive for their life satisfaction, thus resulting in a zero correlation between the two variables. The positive association between perceived daughters' approval and mothers' life satisfaction can be explained by the strong affective ties between the family members (Hwang, 1999; Wang \& Hsueh, 2000).

For Indonesian mothers, the positive association between providing financial support and life satisfaction is in line with several studies (Mulder, 1992; Schröder-Butterfill, 2003). The Indonesian value system prescribes high responsibility of parents for their children over the whole life span; it is of primary importance for parents to take care of the quality of life of their children. To be able to provide financial support is therefore also important for the life satisfaction of Indonesian mothers. Traditionally, Indonesian parents do not expect that their children will reciprocate their support. However, as shown here, in the urban area but not in the rural area the mothers felt more satisfied when they were perceived to be appreciated by their daughters. As described before, respect for the parents is traditionally expected of the children. However, although respect refers to the social role, admiration operationalized here as the expression of positive evaluation refers much more to the individual attributes. Thus, the direct expression of admiration (comparable to the direct expression of praise) might be a more important characteristic of communication in individualistic cultures or of those cultures, which have undergone social change toward more individualism (Trommsdorff \& Rothbaum, 2008). This interpretation is supported by the fact that the rural Indonesian mothers reported the lowest admiration of all subsamples.

For German mothers, to be a provider of instrumental support seems to be positive for elderly mothers. This is in line with earlier studies in the Western cultural context (Efklides et al., 2003; Lowenstein et al., 2007). Especially the provision of instrumental support can increase the subjective experience of activity, independence, and self-efficacy of the person providing help. This may also be related to the ability to reciprocate received support, which may be especially important in Western cultures. Beyond these outcomes, our study also shows that the provision of instrumental support is positive for life satisfaction because it improves the relationship quality (here admiration by daughters).

However, after controlling for admiration, emotional support given was negatively related to life satisfaction. The concepts of emotional support and relationship quality show a strong conceptual overlap. Thus, above and beyond increasing the relationship quality, the fact that mothers have to provide emotional support may mean that the daughters are experiencing negative life events or suffering from poor mental or emotional health and need comfort. Thus, this may directly impair mothers' life satisfaction, overriding any potential benefit from providing support. 
In sum, the present study broadens our perspective on culture-specific patterns of intergenerational relationships, a main goal of the VOC study (Trommsdorff \& Nauck, 2005). This broadened perspective focuses on the culture-specific meanings of intergenerational relations and, more specifically, the cultural meaning of providing support for the older mothers' well-being.

Some limitations of the present study should be mentioned. Most importantly, the present data are cross-sectional in nature, thus precluding definitive conclusions with regard to causality for the association between provision of support and life satisfaction. Moreover, the reliability of the one-item indicators remains unclear. Of course, we also cannot generalize our results to the whole populations of China, Indonesia, or Germany. Especially for China and Indonesia, intracultural comparisons are definitely necessary. Here, we have compared only rural and urban samples and found urban-rural differences in only the Indonesian sample.

Nevertheless, the present results highlight similarities as well as differences between and within the cultural groups. Cross-cultural research has not often been done with respect to the question of whether elders' provision of social support is associated with their well-being. Our contribution to the VOC study has provided further evidence for the psychological importance of intergenerational support given by elderly people for their adult children. Elderly people often remain active and helpful participants in their families. Therefore, it would be inadequate to regard elderly people as just passive recipients of help. However, the results of our study underline the fact that different consequences of providing help for the provider's life satisfaction have to be considered. Instrumental support and financial support seem to have more positive effects whereas emotional support sometimes can be a burden. However, the quality of the resulting life satisfaction depends not only on the kind of support but also on the cultural background with its underlying value orientations and traditions regarding intergenerational relationships. It seems to be beneficial for the provider when providing support is in line with the cultural expectations and traditional support patterns. However, further research should investigate the assumption on the positive effect of cultural fit between cultural values and providing support.

\section{Acknowledgments}

Parts of this work were previously presented at the Conference of the International Society for the Study of Behavioural Development, July 2008, Würzburg, Germany. We thank Vanessa Silberschneider and Nathalie Brès for their editorial help with the article and Kristen Lavallee for linguistic editing.

\section{Declaration of Conflicting Interests}

The author(s) declared no potential conflicts of interest with respect to the authorship and/or publication of this article.

\section{Funding}

This research was supported by a grant from the Deutsche Forschungsgemeinschaft (TR 169/9-1-3) to the third author. The research is based on the Value of Children and Intergenerational Relationships study (principal investigators Gisela Trommsdorff, University of Konstanz and Bernhard Nauck, Technical University of Chemnitz).

\section{References}

Aiken, L. S., \& West, S. G. (1991). Multiple regression: Testing and interpreting interactions. Newbury Park, CA: Sage.

Albert, I., Trommsdorff, G., Mayer, B., \& Schwarz, B. (2005). Value of children in urban and rural Indonesia: Socio-demographic indicators, cultural aspects, and empirical findings. In G. Trommsdorff \& B. Nauck (Eds.), The value of children in cross-cultural perspective. Case studies from eight societies (pp. 171-207). Lengerich, Germany: Pabst Science. 
Askham, J., Ferring, D., \& Lamura, G. (2007). Personal relationships in later life. In J. Bond, S. M. Peace, F. Dittman-Kohli, \& G. J. Westerhof (Eds.), Ageing in society: An introduction to social gerontology (3rd ed., pp. 186-208). London, UK: Sage.

Baron, R. M., \& Kenny, D. A. (1986). The moderator-mediator variable distinction in social psychological research: Conceptual, strategic, and statistical considerations. Journal of Personality and Social Psychology, 51, 1173-1182.

Bundesinstitut für Bevölkerungsforschung. (2008). Bevölkerung: Daten, Fakten, Trends zum demographischen Wandel in Deutschland [Population: Figures, facts, trends of demographical change in Germany]. Retrieved from http://www.bib-demografie.de/cln_099/nn_750446/SharedDocs/Publikationen/ DE/Download/Broschueren/bev3_2008.html

Caprara, G. V., \& Steca, P. (2006). The contribution of self-regulatory efficacy beliefs in managing affect and family relationships to positive thinking and hedonic balance. Journal of Social and Clinical Psychology, $25,603-627$.

Central Intelligence Agency. (2004). The world factbook. Retrieved from https://www.cia.gov/library/ publications/the-world-factbook/

Chen, X., \& Silverstein, M. (2000). Intergenerational social support and the psychological well-being of older parents in China. Research on Aging, 22, 43-65.

Diener, E. (2000). Subjective well-being: The science of happiness and a proposal for a national index. American Psychologist, 55, 34-43.

Diener, E., Gohm, C. L., Suh, E., \& Oishi, S. (2000). Similarity of the relations between marital status and subjective well-being across cultures. Journal of Cross-Cultural Psychology, 31, 419-436.

Diener, E., Suh, E. M., Lucas, R. E., \& Smith, H. L. (1999). Subjective well-being: Three decades of progress. Psychological Bulletin, 125, 276-302.

Efklides, A., Kalaitzidou, M., \& Chankin, G. (2003). Subjective quality of life in old age in Greece: The effect of demographic factors, emotional state and adaptation to aging. European Psychologist, 8, 178-191.

Ferring, D., Balducci, C., Burholt, V., Wenger, C., Thissen, F., Weber, G., \& Hallberg, I. (2004). Life satisfaction of older people in six European countries: Findings from the European study of adult well-being. European Journal of Ageing, 1, 15-25.

Fujita, F., \& Diener, E. (2005). Life satisfaction set point: Stability and change. Journal of Personality and Social Psychology, 88, 158-164.

Fuligni, A. J., Yip, T., \& Tseng, V. (2002). The impact of family obligation on the daily activities and psychological well-being of Chinese American adolescents. Child Development, 73, 302-314.

Furman, W., \& Buhrmester, D. (1985). Children's perceptions of the personal relationships in their social networks. Developmental Psychology, 21, 1016-1024.

Geertz, H. (1961). The Javanese family: A study of kinship and socialization. Glencoe, IL: Free Press.

Ho, D. Y. F. (1996). Filial piety and its psychological consequences. In M. H. Bond (Ed.), The handbook of Chinese psychology (pp. 155-165). Hong Kong, China: Oxford University Press.

Hofstede, G. (2001). Cultures consequences: Comparing values, behaviors, institutions, and organizations across nations (2nd ed.). Thousand Oaks, CA: Sage.

Hsu, H.-C. (2007). Exploring elderly people's perspectives on successful ageing in Taiwan. Ageing \& Society, 27, 87-102.

Hwang, K.-K. (1999). Filial piety and loyalty: Two types of social identification in Confucianism. Asian Journal of Social Psychology, 2, 163-183.

Klaus, D., Nauck, B., \& Klein, T. (2005). Families and the value of children in Germany. In G. Trommsdorff \& B. Nauck (Eds.), The value of children in cross-cultural perspective. Case studies from eight societies (pp. 17-42). Lengerich, Germany: Pabst Science.

Kohli, M., Künemund, H., Motel, A., \& Szydlik, M. (2000). Families apart? Intergenerational transfer in East and West Germany. In S. Arber \& C. Attias-Donfut (Eds.), The myth of generational conflict. The family and state in ageing societies (pp. 88-99). London, UK: Routledge. 
Kreager, P. (2006). Migration, social structure and old-age support networks: A comparison of three Indonesian communities. Ageing \& Society, 26, 37-60.

Kunzmann, U., Little, T. D., \& Smith, J. (2000). Is age-related stability of subjective well-being a paradox? Cross-sectional and longitudinal evidence from the Berlin Aging Study. Psychology and Aging, 15, 511-526.

Lang, F. R., \& Carstensen, L. L. (2002). Time counts: Future time perspective, goals, and social relationships. Psychology and Aging, 17, 125-139.

Lang, F. R., \& Schütze, Y. (2002). Adult children's supportive behaviors and older parents' subjective well-being-A developmental perspective on intergenerational relationships. Journal of Social Issues, 58, 661-680.

Lowenstein, A., Katz, R., \& Gur-Yaish, N. (2007). Reciprocity in parent-child exchange and life satisfaction among the elderly: A cross-national perspective. Journal of Social Issues, 63, 865-883.

Magnis-Suseno, F. (1989). Neue Schwingen für Garuda: Indonesien zwischen Tradition und Moderne [New wings for Garuda: Indonesia between tradition and modernity]. Munich, Germany: Kindt.

Mayer, B., Albert, I., Trommsdorff, G., \& Schwarz, B. (2005). Value of children in Germany: Dimensions, comparison of generations, and relevance for parenting. In G. Trommsdorff \& B. Nauck (Eds.), The value of children in cross-cultural perspective. Case studies from eight societies (pp. 43-66). Lengerich, Germany: Pabst Science.

Midlarsky, E., \& Kahana, E. (1994). Altruism in later life. Thousand Oaks, CA: Sage.

Mulder, N. (1992). Individual and society in Java: A cultural analysis. Yogyakarta, Indonesia: Gadjah Mada University Press.

Mulder, N. (2000). Inside Southeast Asia: Religion, everyday life, cultural change. Chiang Mai, Thailand: Silkworm Books.

Nauck, B. (2005). Changing values of children: An action theory of fertility behavior and intergenerational relationships in cross-cultural comparisons. In W. Friedlmeier, P. Chakkarath, \& B. Schwarz (Eds.), Culture and human development. The importance of cross-cultural research to the social sciences (pp. 183-202). Hove, UK: Psychology Press.

Oyserman, D., Coon, H. M., \& Kemmelmeier, M. (2002). Rethinking individualism and collectivism: Evaluation of theoretical assumptions and meta-analyses. Psychological Bulletin, 128, 3-72.

Perrig-Chiello, P. (1997). Wohlbefinden im Alter: Körperliche, psychische und soziale Determinanten und Ressourcen [Well-being in old age: Physical, psychological, and social determinants and resources]. Weinheim, Germany: Juventa.

Pidada, S. U. (1993). Mütterliche Erziehungsbedingungen für prosoziale Motivation: eine empirische Untersuchung bei 9-10jährigen Kindern und deren Müttern in Bandung (Indonesien) [Maternal parenting conditions for prosocial motivation: An empirical study of 9-10 year old children and their mothers in Bandung (Indonesia)]. Unpublished doctoral dissertation, Saarland University, Saarbrücken, Germany.

Population Reference Bureau. (2008). 2008 world population data sheet. Retrieved from http://www.prb .org/pdf07/07WPDS_Eng.pdf

Rossi, A. S., \& Rossi, P. H. (1990). Of human bonding. Parent-child relations across the life course. New York, NY: Aldine.

Rowe, J. W., \& Kahn, R. L. (1998). Successful aging. New York, NY: Pantheon.

Ryff, C., \& Keyes, C. L. (1995). The structure of psychological well-being revisited. Journal of Personality and Social Psychology, 69, 719-727.

Schilling, O. (2006). Development of life satisfaction in old age: Another view on the "paradox." Social Indicators Research, 75, 241-271.

Schröder-Butterfill, E. (2003). "Pillars of the family"-Support provided by the elderly in Indonesia (Working Paper WP303). Retrieved from http://www.ageing.ox.ac.uk

Schwarz, B., \& Trommsdorff, G. (2005). Intergenerationaler Austausch von Unterstützung und Reziprozität im Kulturvergleich [Intergenerational exchange of support and reciprocity in a cross-cultural 
perspective]. In A. Steinbach (Ed.), Generatives Verhalten und Generationenbeziehungen (pp. 199-212). Wiesbaden, Germany: VS Verlag für Sozialwissenschaften.

Schwarz, B., Trommsdorff, G., Albert, I., \& Mayer, B. (2005). Adult parent-child relationship: Relationship quality, support, and reciprocity. Applied Psychology: An International Review, 54, 396-417.

Schwarz, B., Trommsdorff, G., Kim, U., \& Park, Y.-S. (2006). Intergenerational support: Psychological and cultural analyses of Korean and German women. Current Sociology, 54, 315-340.

Schwarz, B., Trommsdorff, G., Zheng, G., \& Shi, S. (in press). Reciprocity in intergenerational support: A comparison of Chinese and German adult daughters. Journal of Family Issues.

Sheng, X. (2005). Families and intergenerational relationships in China. Globalization, tradition, social transformation, and elderly care. In A. Steinbach (Ed.), Generatives Verhalten und Generationenbeziehungen (pp. 213-232). Wiesbaden, Germany: VS Verlag für Sozialwissenschaften.

Suh, E., Diener, E., Oishi, S., \& Triandis, H. (1998). The shifting basis of life satisfaction judgments across cultures: Emotions versus norms. Journal of Personality and Social Psychology, 74, 482-493.

Sun, R. (2002). Old-age support in contemporary urban China from both parents' and children's perspectives. Research on Aging, 24, 337-359.

Tesch-Römer, C., Motel-Klingebiel, A., \& von Kondratowitz, H.-J. (2002). Die Bedeutung der Familie für die Lebensqualität alter Menschen im Gesellschafts- und Kulturvergleich [The importance of the family for the quality of life of elderly people in a societal and cultural comparison]. Zeitschrift für Gerontologie und Geriatrie, 35, 335-342.

Trommsdorff, G. (1998). Social and psychological aspects of ongoing changes in Japan: Introduction. In G. Trommsdorff, W. Friedlmeier, \& H.-J. Kornadt (Eds.), Japan in transition: Social and psychological aspects (pp. 11-21). Lengerich, Germany: Pabst Science.

Trommsdorff, G. (2006). Parent-child relations over the life-span. A cross-cultural perspective. In K. H. Rubin \& O. B. Chung (Eds.), Parenting beliefs, behaviors, and parent-child relations. A cross-cultural perspective (pp. 143-183). New York, NY: Psychology Press.

Trommsdorff, G., \& Nauck, B. (2005). The value of children in cross-cultural perspective. Case studies from eight societies. Lengerich, Germany: Pabst Science.

Trommsdorff, G., \& Rothbaum, F. (2008). Development of emotion regulation in cultural context. In M. Vandekerckhove, C. Von Scheve, S. Ismer, S. Jung, \& S. Kronast (Eds.), Regulating emotions: Culture, social necessity, and biological inheritance (pp. 85-120). Oxford, UK: Blackwell.

Trommsdorff, G., \& Schwarz, B. (2007). A study on the "intergenerational stake hypothesis" in Indonesia and Germany: Adult daughters' and their mothers' perception of their relationship. Current Sociology, 55, 599-620.

Umberson, D. (1992). Relationship between adult children and their parents: Psychological consequences for both generations. Journal of Marriage and Family, 54, 664-674.

Van de Vijver, F. J. R., \& Leung, K. (1997). Methods and data analysis for cross-cultural research. Thousand Oaks, CA: Sage.

Wang, Q., \& Hsueh, Y. (2000). Parent-child interdependence in Chinese families: Change and continuity. In C. Violato, E. Oddone-Paolucci, \& M. Genuis (Eds.), The changing family and child development (pp. 60-69). Aldershot, UK: Ashgate.

Yeung, G. T. Y., \& Fung, H. H. (2007). Social support and life satisfaction among Hong Kong Chinese older adults: Family first? European Journal of Ageing, 4, 219-227.

Yue, X., \& Ng, S. H. (1999). Filial obligations and expectations in China: Current views from young and old people in Beijing. Asian Journal of Social Psychology, 2, 215-226.

Zhang, L. (2005). Prediction of Chinese life satisfaction: Contribution of collective self-esteem. International Journal of Psychology, 40, 189-200.

Zhang, Q. F. (2004). Economic transitions and new patterns of parent-adult child coresidence in urban China. Journal of Marriage and Family, 66, 1231-1245.

Zheng, G., Shi, S., \& Tang, H. (2005). Population development and the value of children in the People's Republic of China. In G. Trommsdorff \& B. Nauck (Eds.), The value of children in cross-cultural perspective. Case studies from eight societies (pp. 239-282). Lengerich, Germany: Pabst Science. 


\section{Bios}

Beate Schwarz received her PhD in developmental psychology at the University of Giessen, Germany, and is an assistant professor of developmental psychology at the University of Basel, Switzerland. Her research interests lie in the areas of adolescent development, family psychology, and cross-cultural psychology.

Isabelle Albert received her PhD in developmental and cross-cultural psychology at the University of Konstanz, Germany. She is now employed as a postdoctoral research assistant at the University of Luxembourg, Luxembourg. Her main research interests are in the fields of intergenerational transmission of values, intergenerational relations, and personality and family development in cross-cultural comparison.

Gisela Trommsdorff is professor at the Department of Psychology, University of Konstanz; research professor, DIW Berlin (GSOEP); and president of the German-Japanese Society for Social Sciences. Her research interests include cross-cultural studies on values, intergenerational relations, development of selfregulation, prosocial motivation, and emotions.

Gang Zheng is senior investigator and associate professor at the Research Center of Human Development and Education, Institute of Psychology, Chinese Academy of Sciences in Beijing, People's Republic of China. His research interests lie in international studies on the value of children in cultural contexts, the study of parenting goals in only-child families, and the study of the intergenerational change and/or transition of values in the Chinese population.

Shaohua Shi received her master's degree in psychology from the Graduate University of the Chinese Academy of Sciences and is now senior investigator and associate professor at the Research Center of Human Development and Education, Institute of Psychology, Chinese Academy of Sciences in Beijing, People's Republic of China. Her research interests lie in the value of children in cultural contexts, parenting styles (e.g., consuming behaviors) and their influence on child development, and the addictive behavior of children with Internet games.

Peter R. Nelwan is head of the Developmental Psychology Section at the Faculty of Psychology, Padjadjaran University, Bandung, Indonesia. His research interests include social cognitive development, community psychology, and cross-cultural as well as cultural psychology. 